\title{
An Integrated Optimal Energy Management/Gear-Shifting Strategy for an Electric Continuously Variable Transmission Hybrid Powertrain Using Bacterial Foraging Algorithm
}

\author{
Syuan-Yi Chen, ${ }^{1}$ Yi-Hsuan Hung, ${ }^{2}$ and Chien-Hsun $\mathrm{Wu}^{3}$ \\ ${ }^{1}$ Department of Electrical Engineering, National Taiwan Normal University, Taipei 106, Taiwan \\ ${ }^{2}$ Department of Industrial Education, National Taiwan Normal University, Taipei 106, Taiwan \\ ${ }^{3}$ Department of Vehicle Engineering, National Formosa University, Yunlin 63201, Taiwan \\ Correspondence should be addressed to Yi-Hsuan Hung; hungyh@ntnu.edu.tw
}

Received 17 June 2016; Revised 10 August 2016; Accepted 16 August 2016

Academic Editor: Giuseppe Vairo

Copyright ( 2016 Syuan-Yi Chen et al. This is an open access article distributed under the Creative Commons Attribution License, which permits unrestricted use, distribution, and reproduction in any medium, provided the original work is properly cited.

\begin{abstract}
This study developed an integrated energy management/gear-shifting strategy by using a bacterial foraging algorithm (BFA) in an engine/motor hybrid powertrain with electric continuously variable transmission. A control-oriented vehicle model was constructed on the Matlab/Simulink platform for further integration with developed control strategies. A baseline control strategy with four modes was developed for comparison with the proposed BFA. The BFA was used with five bacterial populations to search for the optimal gear ratio and power-split ratio for minimizing the cost: the equivalent fuel consumption. Three main procedures were followed: chemotaxis, reproduction, and elimination-dispersal. After the vehicle model was integrated with the vehicle control unit with the BFA, two driving patterns, the New European Driving Cycle and the Federal Test Procedure, were used to evaluate the energy consumption improvement and equivalent fuel consumption compared with the baseline. The results show that $[18.35 \%, 21.77 \%]$ and $[8.76 \%, 13.81 \%]$ were improved for the optimal energy management and integrated optimization at the first and second driving cycles, respectively. Real-time platform designs and vehicle integration for a dynamometer test will be investigated in the future.
\end{abstract}

\section{Introduction}

The hybridization of power sources, energy sources, and system configurations for green vehicles has become a mature technology because of outstanding performance (long traveling distance, energy recovery, superior acceleration, optimal control, favorable fuel economy, and low or zero emission) [1-4]. Engine/motor hybrid powertrains constitute the most popular type because of the low level of modification from vehicles with traditional engines. Three configurations (serial, parallel, and power-split or dual-mode) were developed and studied [5]. Various types of advanced vehicle powertrains have been developed to improve the energy usage including electric continuously variable transmission (e-CVT) powersplit hybrid systems $[6,7]$. Considering complexity and system efficiency, this study chose parallel hybrid powertrains for control strategy implementation. Because engine fuel consumption was critical to overall system performance, an e-CVT was equipped downstream of the engine to properly shift the operation points to the efficient area.

For energy management (supervisory control) among power (energy) sources of a vehicle control unit (VCU) for a hybrid powertrain, rule-based control (defined as our baseline control), theoretical control, and combined rulebased/theoretical control are the three main categories of control laws. For the rule-based control category, "if-elsethen" strategies were designed by investigating the performance maps of key components (engine BSFC map and motor efficiency map) [8]. Fuzzy-logic rules are another type for intelligent energy management, especially for highly nonlinear or complicated vehicle powertrains [9]. The benefits of this category are fast rule designs and easy implementation for VCUs. However, managing complicated vehicle systems with various control variables is difficult. For 
the theoretical analysis category, deterministic dynamic programming (DDP) for the hybrid powertrain is regarded as the "absolute" optimization in a preset scenario (or driving cycle) [10]. A genetic algorithm (GA) is another theoretical method for analyzing hybrid powertrain control [11]. The benefit of this category is that it can be used to solve complicated problems with several variables, and the analyzed results are more convincing. However, the heavy computational load limits this category for online control. Furthermore, how offline optimal results are implemented in online strategies is crucial. The control rules after a ruleextraction procedure cannot guarantee optimization. For the third category (combined rule-based/theoretical control) analyzed optimal results can be directly implemented in the VCU for vehicle control. With theories involved in control laws, suboptimal output performance can be expected. The first method is the equivalent consumption minimization strategy [12]. The global search of the maximal (or minimal) cost function derives the optimal control results. A set of multidimensional tables can be implemented in the VCU directly. Modified from DDP, another online optimization method, stochastic dynamic programming, was used for hybrid power distribution [13]. Applying the probability distribution concept can make online control accessible and reduce large computational load, which leads to real-time computation.

Recently, many biologically inspired optimization algorithms have been developed because of their highly efficient computation, global optimization, and wide applications for various industrial fields $[14,15]$. Frequently used natureinspired optimization algorithms include GAs [16], particle swarm optimization (PSO) [17], ant colony optimization [18], differential evolution [19], and bacterial foraging algorithms (BFAs) [20, 21]. The first BFA was proposed by Professor Passino in 2002 and was inspired by the social foraging behavior of Escherichia coli bacteria [20]. During the lifetime of bacteria, they communicate with each other and compete for food simultaneously. After some generations of evolution, bacteria with poor foraging strategies either are eliminated or develop improved foraging strategies. Because BFA uses the intelligence of bionic bacteria; it demonstrates advantages such as parallel search, ease of jumping out of local minima, insensitivity to initial value, and high global optimization ability. Recently, BFAs have been successfully applied to numerous engineering problems such as power system stabilization and control [21-24], vehicle routing [25], operation optimization of wind turbines [26], electric drives control [27, 28], robot control [29], power electronic control [30], fault diagnosis [31], optimal arrangement of distributed generation system [32], and energy management of hybrid electric vehicles [33]. Comparing to the traditional approaches, the applications using BFA can obtain the advantages in terms of the high performance robustness and precision under the dynamic changes of the system [28].

In [33], although a genetic-based BFA was proposed to control the stored battery power of hybrid electric vehicles to achieve higher fuel economy and lower pollutants, the dynamic online control for practical usage must still be verified. Different from [33], the online control for two driving cycles, two BFA control variables, and new vehicle types (e-CVT hybrid electric vehicles [HEVs]) has been conducted. Thus far, few studies have used online BFAs to directly optimize the energy management of hybrid electric vehicles.

Compared to our past works, the most closed research is [34], where the rule-based control, particle swarm optimization, and equivalent consumption minimization strategy were utilized for the energy management. The PSO method, another biologically inspired optimization, can save $30+\%$ equivalent fuel consumption for another HEV type. It proves that either PSO or BFA in this research significantly saves equivalent fuel for HEVs. However, this research has one more variable for optimization. In another previous work [35], the optimal control of integrated energy management/mode switch timing in a hybrid powertrain was conducted. The offline global search algorithm was developed for the optimal power-split ratio and operation mode switch. It saves $30+\%$ energy for a new three-power-source HEV.

From the aforementioned studies, the main academic and industrial contributions of this study are summarized as follows: (1) The BFA procedures for solving two-dimensional optimization problems were formulated. (2) The controloriented e-CVT HEV model was developed. (3) The performance of three cases was compared: four-mode rulebased control, traditional CVT HEVs, and e-CVTs. (4) A reduction in energy usage and equivalent fuel consumption was obtained. This study can be implemented in real hybrid powertrains for positive effect of automotive industry in the future. The remainder of this paper is organized as follows: Section 2 describes the configuration of the proposed powertrains with dynamic equations; Section 3 explains the development of the four-mode rule-based control and the BFA procedures for the optimization problem of the e-CVT HEV; Section 4 presents a comparison of three control cases and shows the improvements in energy management and equivalent fuel consumption; and, finally, Section 5 concludes this study and provides the academic and industrial contributions.

\section{Powertrain and System Modeling}

2.1. E-CVT Hybrid Powertrain Configuration. Figure 1 shows a plot of the configuration of the e-CVT hybrid powertrain. A standard driving scenario sends the demanded speed $\left(V_{d}(t)\right)$ to the driver model. The demanded hybrid power $\left(P_{d}(t)\right)$ is calculated by comparing $V_{d}(t)$ and actual speed $\left(V_{a}(t)\right)$ and then is delivered to the VCU. Using $P_{d}(t)$, the transmission rotational speed $\left(N_{t}(t)\right)$, derived from $V_{a}(t)$, and the battery state-of-charge $\left(\mathrm{SOC}_{b}\right)$, three control variables are calculated: (1) engine torque $\left(T_{e}(t)\right),(2)$ motor torque $\left(T_{m}(t)\right)$, and (3) the gear reduction ratio $\left(\mathrm{rr}_{\mathrm{CVT}}\right)$ for e-CVT. The combined torque at the transmission $\left(T_{t}(t)\right)$ accelerates or decelerates the longitudinal vehicle equivalent mass to calculate $V_{a}(t)$. The mode on/off switch for rule-based control is governed by two electric-controlled clutches downstream of the e-CVT and the traction motor. Note that the motor is regarded as a generator if the battery charging power is necessary for maintaining SOC balance. 


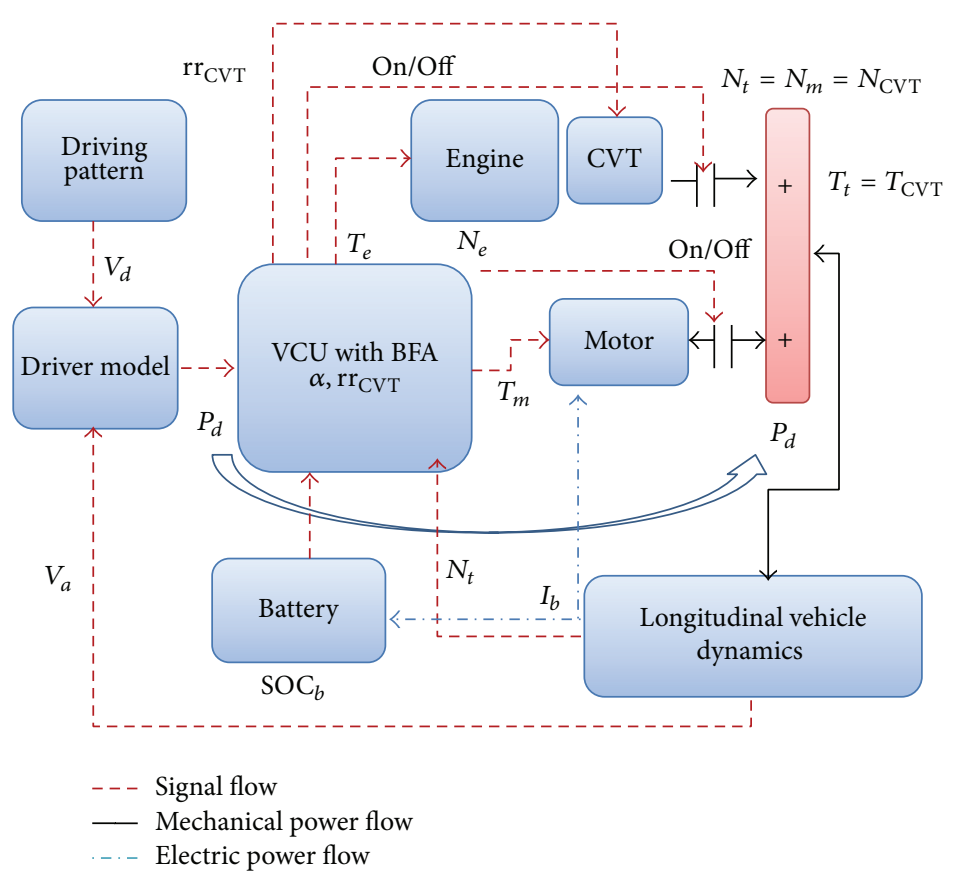

FIGURE 1: e-CVT engine/motor hybrid powertrain system with control.

2.2. System Modeling. Many research papers model the HEV dynamics. Here, five main segments (subsystems and operation scenarios) are modeled for the control-oriented HEV dynamics.

2.2.1. Driving Cycle and Driver Behavior. A driving cycle is the standard testing scenario that can provide objective data for performance evaluation. The demanded speed is only a function of time: $V_{d}=V_{d}(t)$. Driver behavior, which was not the main focus of this research, can be set as a proportionalintegral (PI) controller with the vehicle speed error input between $V_{d}$ and $V_{a}\left(\Delta V \equiv V_{d}-V_{a}\right)$. The demanded hybrid power is determined using the following formula:

$$
P_{d}(t)=G_{\mathrm{pwr}}\left[K_{p}(\Delta V)+K_{I} \int_{0}^{t}(\Delta V) d t\right],
$$

where $G_{\text {pwr }}, K_{p}$, and $K_{I}$ are the gain from the throttle (or brake) in response to the demanded power, the proportional gain of the throttle, and the integral gain of the throttle, respectively. If $P_{d}<0$, the braking force that directly acts on the vehicle mass $\left(m_{v}\right)$ can be formulated as follows:

$$
F_{\text {brk }}(t)=G_{\text {brk }}\left[K_{p} \Delta V+K_{I} \int_{0}^{t}(\Delta V) d t\right] .
$$

2.2.2. Main Power Source: Internal Combustion Engine. A two-dimensional brake specific fuel consumption (BSFC) map represents engine performance, where engine speed $\left(N_{e}\right)$ and engine torque $\left(T_{e}\right)$ are the $x$-axis and $y$-axis, respectively. The BSFC ( $\mathrm{g} / \mathrm{kW}-\mathrm{hr}$ ) is thus expressed in the following formula:

$$
\operatorname{BSFC}(t)=\operatorname{BSFC}\left(N_{e}(t), T_{e}(t)\right) .
$$

To evaluate the accumulated fuel usage and energy consumption, the fuel consumption rate $(\mathrm{g} / \mathrm{s})$ is formulated from the derived BSFC:

$$
\dot{m}_{e}(t)=\operatorname{BSFC}\left(N_{e}(t), T_{e}(t)\right) \times \frac{T_{e}(t) N_{e}(t)}{\left(3.6 \times 10^{6}\right)} .
$$

2.2.3. Traction Motor and High-Power Lithium Battery. Because of the quick response of motor dynamics compared with vehicle mass dynamics, another two-dimensional efficiency map with motor speed $N_{m}(t)$ and torque $T_{m}(t)$ is expressed as follows:

$$
\eta_{m}(t)=f\left(T_{m}(t), N_{m}(t)\right) .
$$

Note that we assume that the efficiencies for charge and discharge conditions are the same. For the energy storage device and electricity provider, a lithium battery was applied in this research and can be expressed as an inner resistance model [36]. The equivalent resistance for charge and discharge $\left(R_{b, \mathrm{chg}}\right.$ and $\left.R_{b, \mathrm{dchg}}\right)$ and the open circuit voltage $\left(V_{b, \mathrm{oc}}\right)$ are influenced by $\mathrm{SOC}_{b}$ and battery temperature. To simplify the problem, the temperature remains at a constant of $25^{\circ} \mathrm{C}$. The battery current $\left(I_{b}\right)$ is derived from battery power $\left(I_{b}\right)$, inner resistance $\left(R_{b}\right)$, and $V_{b, o c}$ :

$$
I_{b}(t)=\frac{\left(V_{b, \mathrm{oc}}\left(\mathrm{SOC}_{b}(t)\right)-\sqrt{V_{b, \mathrm{oc}}^{2}(\mathrm{SOC}(t))-4 R_{b}(t)\left(\mathrm{SOC}_{b}(t)\right) P_{b}(t)}\right)}{2 R_{b}(t)} .
$$


Note that $R_{b}=R_{b \text {,chg }}$ if $P_{b}<0$, whereas $R_{b}=R_{b \text {,dchg }}$ if $P_{b} \geq 0$. Note that $P_{b}$ for discharge $\left(P_{b, \mathrm{dchg}}\right)$ and charge $\left(P_{b, \mathrm{chg}}\right)$ conditions can be expressed, separately, as follows:

$$
\begin{aligned}
P_{b, \mathrm{dchg}}(t) & =\frac{P_{m}(t)}{\eta_{m, \mathrm{dchg}}}=\frac{T_{m}(t) N_{m}(t)}{\eta_{m, \mathrm{dchg}}} \\
P_{b, \mathrm{chg}}(t) & =P_{m}(t) \times \eta_{m, \mathrm{chg}}=T_{m}(t) N_{m}(t) \times \eta_{m, \mathrm{chg}} .
\end{aligned}
$$

The first-order dynamics of the battery are governed by the state $x_{1}: \mathrm{SOC}_{b}$, which is formulated as follows:

$$
\begin{aligned}
x_{1} & =\operatorname{SOC}_{b}(t)=\operatorname{SOC}_{b, \text { init }}-\frac{\int_{0}^{t} I_{b}(t) d t}{Q_{b}} \longrightarrow \\
\dot{x}_{1}(t) & =I_{b}(t),
\end{aligned}
$$

where $\mathrm{SOC}_{b \text {,init }}$ and $\mathrm{Q}_{b}$ are the initial $\mathrm{SOC}_{b}$ and the electric capacity, respectively.

2.2.4. Traditional CVT and e-CVT Systems. CVTs function as an amplifier to properly modify the output torque/speed from the input torque/speed of power sources. Through CVTs, the power sources are expected to work efficiently with the operation points in the efficient zones. Traditional CVTs mainly consist of a driving pulley, driven pulley, and rubber belt or steel chain [37]. The rollers in the rotating driving pulley push the moving flange by centrifugal force. Because the length of the CVT belt is fixed, the moving flange of the driven pulley overcomes the compression force of a torsional spring. Both equivalent radiuses of the belt on the driving and driven flanges form a reduction ratio. The reduction ratio $\left(\mathrm{rr}_{\mathrm{CVT}}\right)$ and efficiency $\left(\eta_{\mathrm{CVT}}\right)$ are functions of the torque and speed of the CVT output shaft:

$$
\begin{gathered}
\operatorname{rr}_{\mathrm{CVT}}=\operatorname{rr}_{\mathrm{CVT}}\left(N_{\mathrm{CVT}}, T_{\mathrm{CVT}}\right), \\
\eta_{\mathrm{CVT}}=\eta_{\mathrm{CVT}}\left(N_{\mathrm{CVT}}, T_{\mathrm{CVT}}\right),
\end{gathered}
$$

where $T_{t}$ and $N_{t}$ denote the torque and speed of the transmission, respectively. Therefore, the relationships of the torques and speeds upstream (CVT) and downstream (transmission) are expressed as follows:

$$
\begin{aligned}
T_{e} & =\frac{T_{\mathrm{CVT}}}{\left(\eta_{\mathrm{CVT}} \mathrm{rr}_{\mathrm{CVT}}\right)}, \\
N_{e} & =\mathrm{rr}_{\mathrm{CVT}} N_{t} .
\end{aligned}
$$

Note that from Figure 1, the rotational speeds upstream of transmission, downstream of CVT, and of the motor shaft are the same because they are directly interconnected $\left(N_{t}=\right.$ $\left.N_{\text {CVT }}=N_{m}\right)$. For the e-CVT, the working principles are similar except that the movements of the moving flanges of the driving pulley and driven pulley are controlled by two servo actuators. Therefore, $\mathrm{rr}_{\mathrm{CVT}}$ varies by sending the control voltages to the actuator motors from the VCU.

2.2.5. Transmission and Vehicle Mass Dynamics. A transmission downstream of the e-CVT and traction motor is regarded as a pair of reduction gears with a fixed reduction ratio, $\mathrm{rr}_{t}$, that relates to $T_{t}$, wheel torque $\left(T_{w}\right)$, transmission speed $\left(N_{t}\right)$, and wheel speed $\left(N_{w}\right)$, through the following expression:

$$
\begin{aligned}
T_{w}(t) & =T_{t}(t) \times \mathrm{rr}_{t} \times \eta_{t} \\
& =\left[T_{m}(t)+T_{\mathrm{CVT}}(t)\right] \times \mathrm{rr}_{t} \times \eta_{t} \\
N_{t}(t) & =N_{m}=N_{w} \times \mathrm{rr}_{t}=\frac{V_{v}}{r_{w}} \times \mathrm{rr}_{t}
\end{aligned}
$$

where $\eta_{t}$ is the efficiency of transmission and $V_{v}$ and $r_{w}$ are the vehicle speed and wheel radius, respectively. For longitudinal vehicle mass dynamics, a first-order dynamic equation for vehicle speed of the vehicle mass $\left(m_{v}\right)$ is formulated as follows:

$$
\begin{aligned}
\dot{x}_{2}(t) & =a_{v}(t)=\frac{d V_{v}(t)}{d t} \\
& =\frac{\left[T_{w}(t) / r_{w}-F_{\text {brk }}(t)-F_{\text {wind }}(t)-F_{\text {roll }}\right]}{m_{v}} \\
& =\frac{\left[T_{w} / r_{w}-F_{\text {brk }}-0.5 C_{d} \rho A_{f} V_{v}^{2}-\mu m_{v} g\right]}{m_{v}} \longrightarrow \\
x_{2} & \equiv V_{v},
\end{aligned}
$$

where $F_{\text {brk }}, F_{\text {wind }}$, and $F_{\text {roll }}$ are the braking force, wind force, and rolling resistance. The braking force is referred to as (2). The parameters $C_{d}, A_{f}, \rho$, and $\mu$ denote the air drag coefficient, vehicle frontal area, air density, and rolling resistance coefficient, respectively.

\section{Energy Management/Gear-Shifting Control Strategies}

3.1. Baseline Control Strategy with Four Modes. To compare the traditional rule-based control with the BFA optimization, an if-else-then control law was designed based on engineering intuition. It consists of four modes: system ready, electric vehicle (EV), engine only, and hybrid mode. Without any power requirement (no pedal input), the system is in mode 1. Mode $2(\mathrm{EV})$ is mainly switched on at low rotational (vehicle) speeds because of higher traction torque. To maintain the cruising mileage, mode 3 activates the engine only when the speed further increases. At higher rotational speeds, mode 4 operates the engine and motor with a fixed power-split ratio $\left(T_{m}: T_{e}=7: 3\right)$ to achieve higher output performance (higher output torque and power). Table 1 shows the conditions and actions of the four modes.

\subsection{Multidimensional Control Using BFA}

3.2.1. Optimized Control Variables and Relationships of Power Flows. The definitions of designed control variables are formulated. The power-split ratio, $\alpha$, is the first control variable $\left(u_{1}\right)$ for energy management, which is defined as the CVT 
TABLE 1: Four-mode rule-based strategy.

\begin{tabular}{lcc}
\hline Mode & Condition & Action \\
\hline (1) System ready & $P_{d}=0\left(T_{d}=0\right)$ & $T_{m}=0, T_{e}=0$ \\
(2) EV & $T_{d}>0 \& N_{e}<2400$ & $T_{m}=T_{d}, T_{e}=0$ \\
(3) Engine only & $T_{d}>0 \& 1500 \leq N_{e}<3200$ & $T_{m}=0, T_{e}=T_{d}$ \\
(4) Hybrid mode & $T_{d}>0 \& N_{e} \geq 2200$ & $T_{m}=0.7 T_{d}$, \\
& & $T_{e}=0.3 T_{d}$ \\
\hline
\end{tabular}

output power divided by the demanded transmission input power (Figure 1):

$$
\alpha=u_{1} \equiv \frac{P_{\mathrm{CVT}}}{P_{d}}=\frac{T_{\mathrm{CVT}} N_{\mathrm{CVT}}}{T_{d} N_{t}}=\frac{T_{e} \mathrm{rr}_{\mathrm{CVT}} \eta_{\mathrm{CVT}}}{T_{d}} .
$$

Note that $\mathrm{rr}_{\mathrm{CVT}}$ is the second control parameter $\left(u_{2}\right)$ for the e-CVT case. Therefore, the VCU commands for $T_{e}$ and $T_{m}$ are calculated as follows:

$$
\begin{aligned}
T_{e} & =\alpha \times \frac{P_{d}}{\left(N_{t} \mathrm{rr}_{\mathrm{CVT}} \eta_{\mathrm{CVT}}\right)}=\alpha \times \frac{T_{d}}{\left(\mathrm{rr}_{\mathrm{CVT}} \eta_{\mathrm{CVT}}\right)} \\
& =\frac{u_{1} T_{d}}{\left(u_{2} \eta_{\mathrm{CVT}}\right)}, \\
T_{m} & =\frac{P_{m}}{N_{m}}=(1-\alpha) \times \frac{P_{d}}{N_{t}}=\left(1-u_{1}\right) \times \frac{P_{d}}{N_{t}} .
\end{aligned}
$$

Investigation of the value of $\alpha$, the operation modes, and the power flow, and their fuel consumption, according to (1) to (18), yields the following results.

(1) $\alpha=0$ (EV Mode). No engine fuel rate is consumed in this case. The battery power is directly calculated from $P_{d}$ according to (1). The variables $N_{m}$ and $T_{m}$ in $\eta_{m}$ are calculated from (14) and (18), respectively. Therefore, two required variables for equivalent fuel consumptions can be calculated as

$$
\begin{aligned}
& \dot{m}_{e}=0 ; \\
& P_{b}=\frac{P_{d}}{\eta_{m}\left(N_{m}, T_{m}\right)} .
\end{aligned}
$$

(2) $0<\alpha<1$ (Hybrid Mode). According to (4), the engine mass flow rate is calculated by $N_{e}(t)$ and $T_{e}(t)$, which can be derived from (11) and (17), respectively. The battery power is determined using (18):

$$
\begin{aligned}
& \dot{m}_{e}(t)=\operatorname{BSFC}\left(N_{e}(t), T_{e}(t)\right) \times \frac{T_{e}(t) N_{e}(t)}{\left(3.6 \times 10^{6}\right)} ; \\
& P_{b, \text { dchg }}=\frac{(1-\alpha) P_{d}}{\eta_{m}\left(N_{m}, T_{m}\right)} .
\end{aligned}
$$

(3) $\alpha=1$ (Engine Only Mode). The battery power is 0 , and all propulsion power is from the engine.

$$
\begin{aligned}
\dot{m}_{e}(t) & =\operatorname{BSFC}\left(N_{e}(t), T_{e}(t)\right) \times \frac{T_{e}(t) N_{e}(t)}{\left(3.6 \times 10^{6}\right)} ; \\
P_{b} & =0 .
\end{aligned}
$$

(4) $\alpha>1$ (Engine Generation Mode). The engine alone drives the vehicle, and it charges the battery using the motor as a generator.

$$
\begin{aligned}
\dot{m}_{e}(t) & =\operatorname{BSFC}\left(N_{e}(t), T_{e}(t)\right) \times \frac{T_{e}(t) N_{e}(t)}{\left(3.6 \times 10^{6}\right)} ; \\
P_{b, \text { chg }} & =(1-\alpha) P_{d} \times \eta_{m}\left(N_{m}, T_{m}\right) .
\end{aligned}
$$

The power flow equations are similar to (20). However, according to (8) instead of (7), the expression of negative battery power $((1-\alpha)<0)$ is different from that in $(20)$.

3.2.2. BFA Control. The scheme of this study is illustrated in Figure 2. The three main segments are the BFA optimization, the controller, and the controlled plant. The three inputs of the BFA optimization are $V_{a}, \mathrm{SOC}_{b}$, and $P_{d}$ feedback from the plant and the controller. The for-loop-structural program with the mechanisms of elimination-dispersal, reproduction, and chemotaxis is used to derive the two optimal control parameters, $\alpha$ and $\mathrm{rr}_{\mathrm{CVT}}$, within a time step. These parameters were sent to the controller, which consists of two parts. Driver behavior is regarded as a PI controller in determining $P_{d}$. The VCU is responsible for calculating $T_{e}$ and $T_{m}$ from $P_{d}$, $\alpha$, and $\operatorname{rr}_{\mathrm{CVT}}$, as described in Section 3.1, under physical limitations (such as engine maximal speed and torque, and maximal and minimal reduction ratio). The torque together with the optimal $\mathrm{rr}_{\mathrm{CVT}}$ was delivered to the vehicle dynamics to evaluate the system/subsystem performance $V_{a}$ and $\mathrm{SOC}_{b}$. This information is then sent to the BFA optimization for the optimal control in the next step.

3.2.3. BFA Procedure on Energy Management/Gear-Shifting Optimization. To solve the optimal problem of the integrated energy management/gear shifting in an e-CVT hybrid electric powertrain, the BFA was adopted to search the powersplit ratio, $\alpha$, and reduction ratio, $\mathrm{rr}_{\mathrm{CVT}}$, for minimizing equivalent fuel consumption. A BFA algorithm comprises three principal procedures: chemotaxis, reproduction, and elimination-dispersal [20]. A flowchart of the BFA algorithm is shown in Figure 3. For a search space with $d$ dimensions, which is also the number of elements within a bacterium vector $\theta$, the following parameters of the BFA algorithm are initialized first: the number of bacteria in the population is $N_{p}$, the number of chemotactic steps is $N_{c}$, the number of swim or tumble actions in a chemotactic step is $N_{s}$, the number of reproduction steps is $N_{r}$, and the number of elimination-dispersal steps is $N_{e}$. The procedures of the BFA are introduced as follows. 


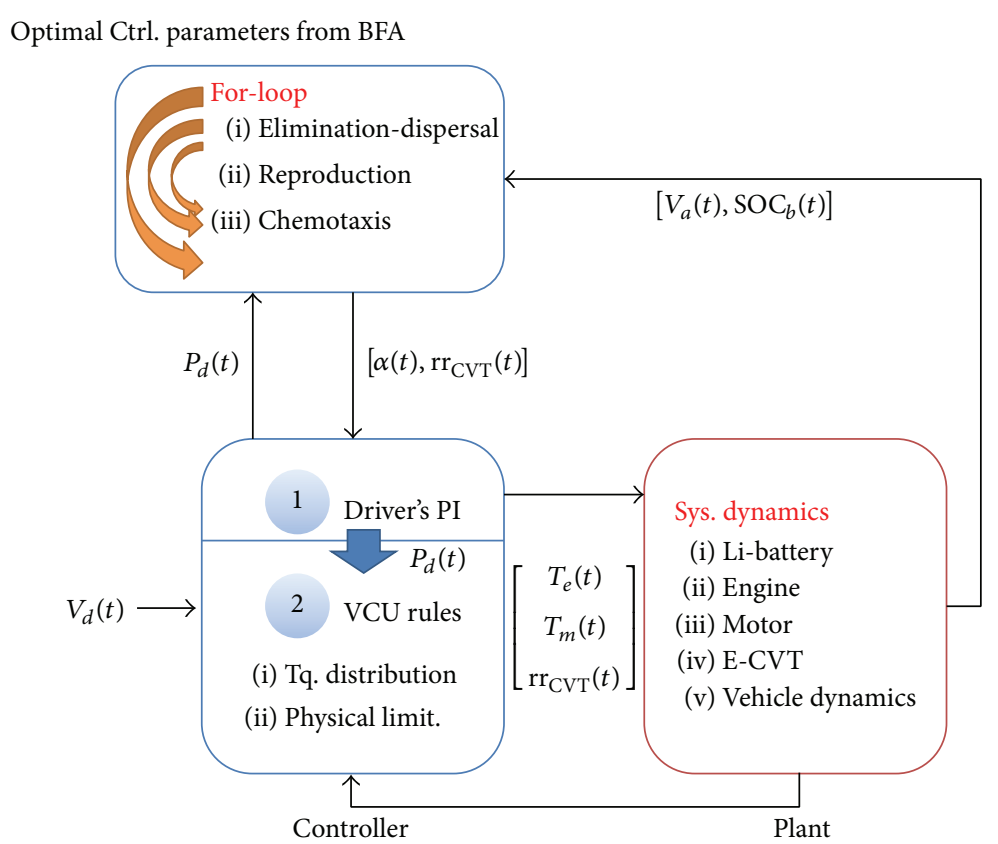

FIGURE 2: Energy management/gear-shifting optimization of BFA.

(1) Chemotactic Loop. During the chemotactic loop process, the bacteria climb the nutrient concentration and avoid noxious substances, instead of searching for neutral media [21]. The bacterium performs tumble or swim actions followed by a tumble action. For each bacterium, the new position after a tumble action can be represented by

$$
\theta_{r}(j+1, k, l)=\theta_{r}(j, k, l)+C(r) \phi(r),
$$

where $\theta_{r}(j, k, l)$ is the position of the $r_{\text {th }}$ bacterium in the $j_{\text {th }}$ chemotactic step in the $k_{\text {th }}$ reproduction and the $l_{\text {th }}$ elimination-dispersal loops; $C$ is the step size of each moving behavior; $\phi(r)$ is the random direction of a tumble action, which is defined as

$$
\phi(r)=\frac{\Delta(r)}{\sqrt{\Delta^{T}(r) \Delta(r)}},
$$

where $\Delta$ is a random step on $[-1,1]$. After the bacterium completes a tumble action, the bacterium performs a swim action (i.e., continuing to move in the same direction), while the fitness value, as shown in (25), is improved. Otherwise, the bacterium performs the tumble again, searching for a new moving direction. The fitness function is modified from [34] as follows:

$$
\begin{aligned}
& \mathrm{FIT}=\frac{1}{\dot{m}_{\mathrm{eq}}} \\
& =\frac{1}{\left[\dot{m}_{e}\left(T_{e}, N_{e}\right)+P_{b} /\left(3.6 \times 10^{6}\right) \times \overline{\mathrm{BSFC}} \times P\left(\mathrm{SOC}_{b}\right)\right]},
\end{aligned}
$$

where $P\left(\mathrm{SOC}_{b}\right)$ is a penalty factor related to the battery SOC. When the SOC value is high, $P\left(\mathrm{SOC}_{b}\right)$ decreases to increase the electricity usage and vice versa. This can balance the SOC throughout the entire driving cycle. Moreover, the variable $\overline{\mathrm{BSFC}}$ is used to perform the unit transformation from $\mathrm{kWh}$ to g. The physical meaning of FIT is the inverse of the equivalent fuel, which is the summation of real engine fuel consumption and the equivalent "battery fuel" consumption (modified from the concept of [12]).

(2) Reproduction Loop. After $N_{c}$ chemotactic steps are completed, reproduction is carried out. First, the fitness values of all the bacteria are sorted in ascending order. Subsequently, bacteria that have fitness values in the lower half die, and the remaining bacteria split into two bacteria that are placed in the same location. This keeps the population size constant.

(3) Elimination-Dispersal Loop. After $N_{r}$ reproduction steps are completed, bacteria are eliminated and dispersed to a new location in the search space if a random probability $P_{r}$ is higher than a predefined threshold $P_{e}$. In that case, it is helpful to jump out of the local optimum and achieve the global optimum.

\section{Simulation Results and Discussion}

4.1. Simulator and Settings. The e-CVT HEV simulator was constructed on the Matlab/Simulink platform. The program structure is shown in Figure 4. The program is separated into four segments. The Matlab data m-file stores vehicle parameters such as the engine and motor performance maps, battery measured data, vehicle information, and driving cycle data. An S-function coded the BFA optimization with a cost (FIT 


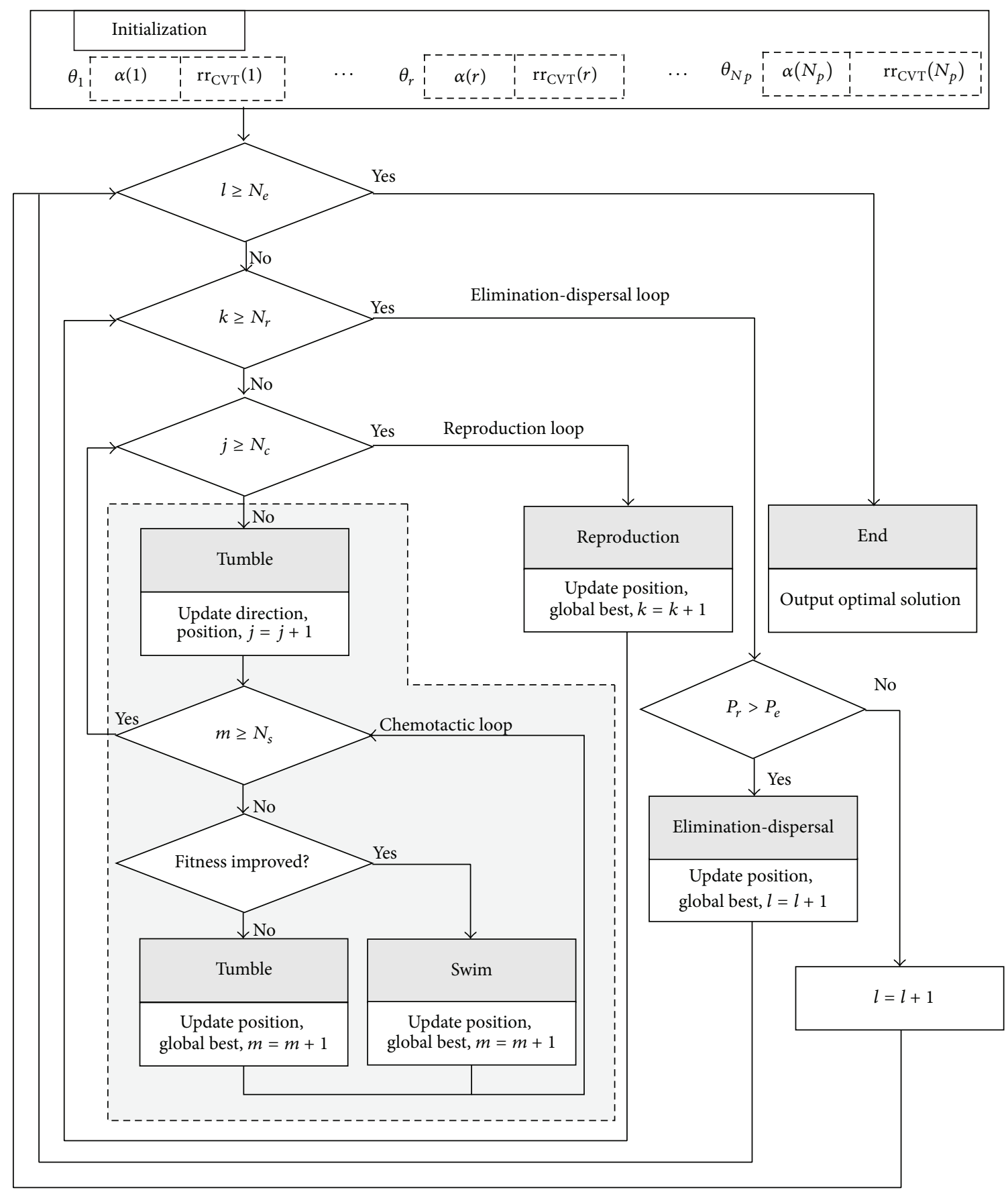

FIGURE 3: BFA procedure for solving optimal problem.

function) function, whereas the data file provided information for calculation. The Simulink program constructed the vehicle dynamics with the subsystems described in Section 2. With the control inputs described in Section 3 to the model, the simulation results can be output. The parameters of the vehicle model were input from the data file as well. The plot $\mathrm{m}$-file finally draws the simulation results for performance analysis. For simulation, the numerical method used was the Runge-Kutta method. Table 2 lists the vehicle parameters and system settings; the parameter values for the BFA described in Section 3 are listed in Table 3.

\subsection{Comparison of Baseline, Optimal Energy Management, and Integrated Control Cases}

4.2.1. BFA Simulation Results. This part demonstrates the detailed simulation results of the BFA described in Section 3.2.3. To show the evolutions of the bacteria using 


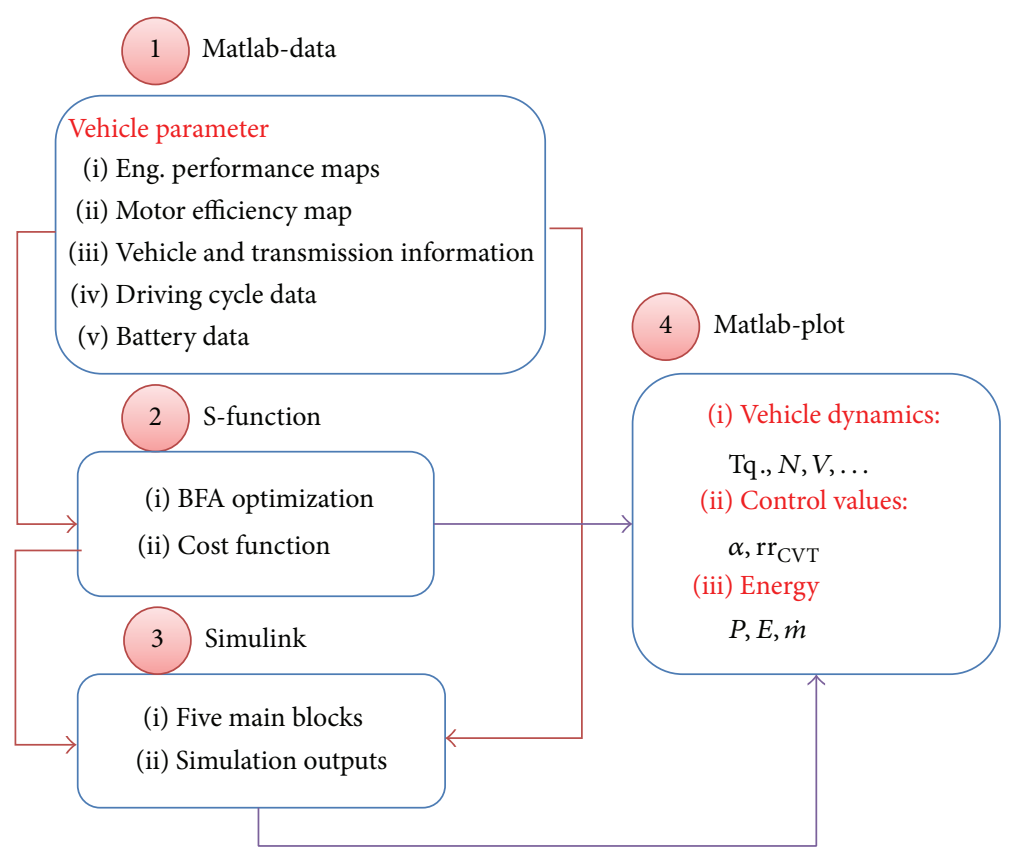

Figure 4: E-CVT HEV simulator on Matlab/Simulink platform.

TABLE 2: Parameter values of targeted vehicle model.

\begin{tabular}{lc}
\hline Parameter & Value \\
\hline$G_{t q}$ & 400 \\
$G_{\text {brk }}$ & 2000 \\
$K_{p}$ & 0.5 \\
$K_{I}$ & 0.2 \\
$\mathrm{rr}_{t}$ & 4.0 \\
$\eta_{t}$ & $90 \%$ \\
$C_{d}$ & 0.335 \\
$A_{f}$ & $2 \mathrm{~m}^{2}$ \\
$\rho$ & $1.225 \mathrm{~kg} / \mathrm{m}^{3}$ \\
$\mu$ & 0.009 \\
$m_{v}$ & $1986 \mathrm{~kg}$ \\
$g$ & $9.81 \mathrm{~m} / \mathrm{s}^{2}$ \\
$r_{w}$ & $0.282 \mathrm{~m}$ \\
$\mathrm{BSFC}$ & $295 \mathrm{~g} / \mathrm{kW}-\mathrm{hr}$ \\
$Q_{b}$ & $25 \mathrm{~A}-\mathrm{h}$ \\
\hline
\end{tabular}

the BFA, the movements of the first five bacteria in the population at the 15th second during the New European Driving Cycle (NEDC) for optimal energy management and optimal energy management/gear-shifting controls are shown in Figures 5 and 6, respectively. In the evolutions, all the bacteria have distinct and random initial positions. According to the optimal energy management via the BFA as shown in Figure 5, one can observe that the bacteria perform tumble and swim actions to search for the optimal powersplit ratio, $\alpha$, individually. The effectiveness of the BFA is demonstrated by the gradual increase in the fitness function during the optimization process. After the 11th iteration, the
TABLE 3: Parameter values of BFA control.

\begin{tabular}{lc}
\hline Parameter & Value \\
\hline$N_{p}$ & 10 \\
$N_{e}$ & 30 \\
$N_{r}$ & 1 \\
$N_{c}$ & 1 \\
$N_{s}$ & 1 \\
$d$ & 1 or 2 \\
$c$ & 0.01 \\
$P_{e}$ & 0.8 \\
Searching space of $\alpha$ & {$[01]$} \\
Searching space of $\mathrm{rr}_{\mathrm{CVT}}$ & {$[0.22 .4]$} \\
\hline
\end{tabular}

fitness function was gradually stable and the optimal powersplit ratio was found. By contrast, the power-split ratio $\alpha$ and reduction ratio $\mathrm{rr}_{\mathrm{CVT}}$ were optimized simultaneously in the optimal energy management/gear-shifting control, as shown in Figure 6. In Figure 6, the initial random points and destination points of bacteria are symbolized by circle and star marks, respectively. The two-dimensional trajectory clearly shows that the bacteria moved and competed in the searching space to find the optimal solution. Of the bacteria $\theta_{1}, \theta_{2}, \theta_{3}$, and $\theta_{5}$, all found the neighboring optimal solutions except bacterium $\theta_{4}$. Similarly, the fitness value during the optimization process was increased gradually.

4.2.2. Output Performance in Driving Patterns. To evaluate the system performance and testing scenarios, driving cycles were selected in advance. Figure 7 presents the two typical driving cycles for the simulation. The first is the NEDC (New European Driving Cycle), whereas the second is the FTP-72 

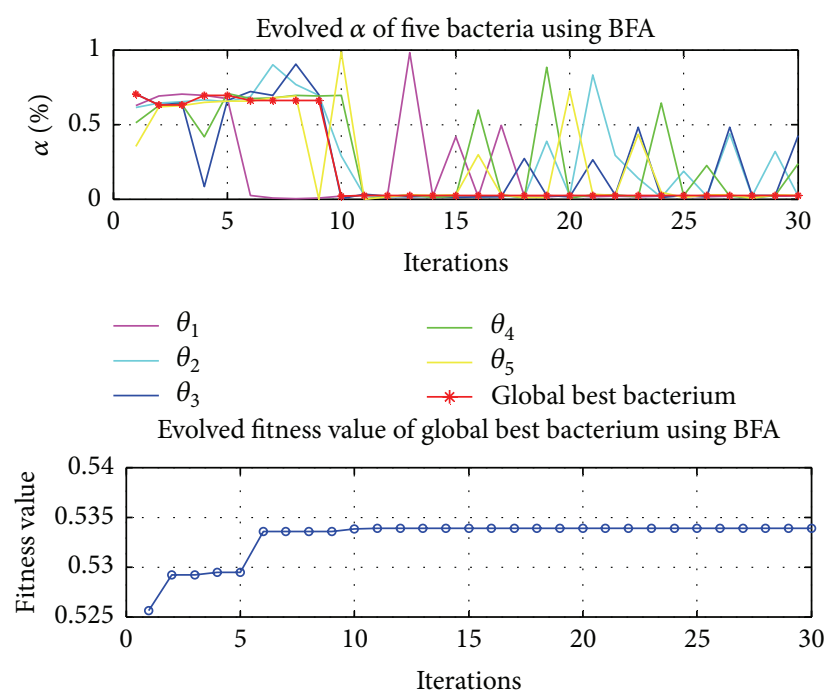

FIGURE 5: BFA results of optimal energy management at the 15th sampling time.
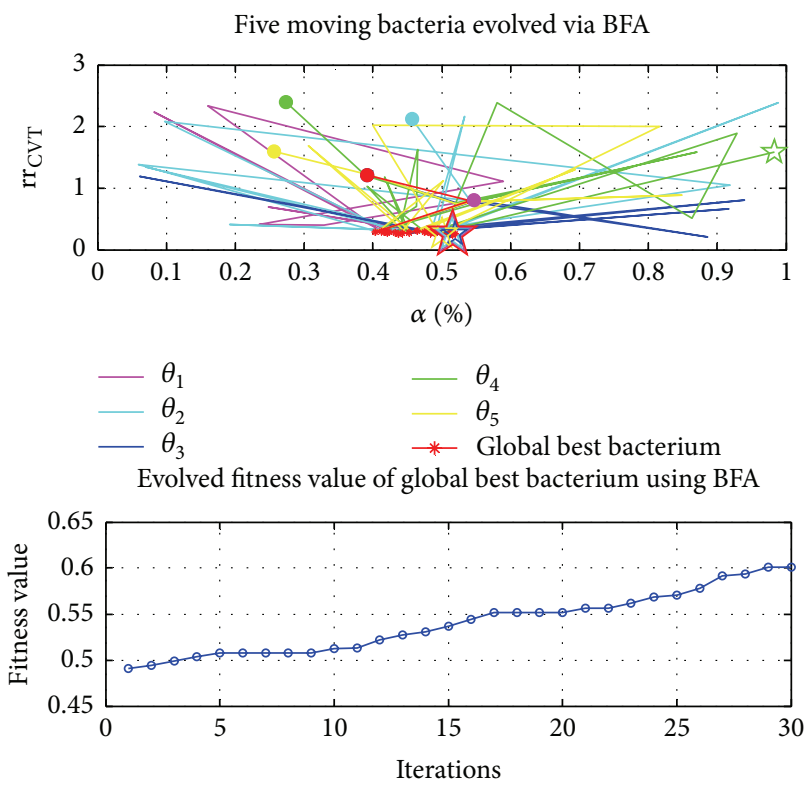

FIGURE 6: BFA results of optimal energy management/gear shifting at the 15 th sampling time.

(Federal Test Procedure) driving cycle. For the NEDC, one cycle is 1180 seconds and the traveling distance is $11.0 \mathrm{~km}$. Many constant-speed periods can be tested. FTP-72 is a city driving program that takes 1369 seconds and has many acceleration/deceleration periods. The traveling distance is $12.07 \mathrm{~km}$.

For the NEDC simulation, three cases were investigated, separately. For rule-based control, Figure 8(a) shows that the vehicle speed tracking was favorable (within $\pm 1.0 \mathrm{~km}$ ); therefore, the following simulation results were convincing. As shown in Figure 8(b), before the 800th second, the motor provided the whole torque (power) at the low-speed period, (mode 2 ) according to Table 1 . Only at medium rotational (vehicle) speed did the engine take charge of the driving power to extend the driving mileage (mode 3). After the 800th second, the engine covered most of the operation because of the high required vehicle speed. After the 1000th second, the higher speed led to the mode switching to the hybrid mode (mode 4 ), where the engine and the motor drove the vehicle simultaneously. The gear ratio of the traditional CVT showed that it varied from 2.4 to around 0.85 , and the profile exhibited an opposite tendency to that of the vehicle speed. The tendency was to switch the engine operation speed in the efficient area. For the battery SOC, after one cycle, the value went from the initial $50 \%$ to $36.8 \%$. The SOC difference was $13.2 \%$. Figure 9 exhibits the operation points of dual power sources. In Figure 9(a), it shows that although the engine operated in a reasonable operation region, many operation points were still located in inefficient areas (i.e., $T_{e} \leq 60 \mathrm{~N} \cdot \mathrm{m}$ $\rightarrow$ BSFC $<350 \mathrm{~g} / \mathrm{kW}-\mathrm{hr}$ ). Moreover, because of the lowspeed (or low-power) operation of mode 2 (motor only), most motor operation points were located in an inefficiency area below 85\%, as shown in Figure 9(b).

For optimal energy management control, compared with Figure 8, Figure 10(a) still shows favorable vehicle speed tracking. However, the torque distribution depicted in Figure 10 is quite different. Despite being in a low-vehicle-speed (low power) area, the motor controlled the main output power and the engine still assisted the motor in reserving the battery energy. In the high-power region, the engine became the main power source to propel the vehicle because the BSFC in the high-torque region was low (it had high fuel efficiency). Especially after the 800th second, the motor was regarded as a power-assist power device. According to the definition in (16), the profile of $\alpha(t)$ shown in Figure 10(c) increased as the power of the engine increased. Equations (17) and (18) are used to determine the torque commands of dual power sources. The gear reduction ratio of the passive CVT showed similar variation to that of the rule-based case. Because the engine operated with more time, the battery SOC dropped from $50 \%$ to $42.4 \%$; hence, the SOC difference after one cycle was 7.6\%. As shown in Figure 11, more engine operation points concentrated in the the region at BSFC $\geq 350 \mathrm{~g} / \mathrm{kW}$-hr. Although the motor operation points were still in an inefficient area for torque (power) assistance, the number of operation points was lower than that in the rule-based case. We expected a more favorable equivalent fuel value from (25) compared with that in the rule-based case.

For optimal energy management/gear-shifting control (integrated control), the torque distribution in Figure 12 was different from the two previous cases. The operation time and power of the engine were longer and larger, respectively. The motor acted only as an assistive power source that provided the compensated power that allowed the engine to operate efficiently. The profile of the first control variable $u_{1}=\alpha(t)$ shows that the $\alpha$ values are, on average, higher than those in the optimal energy management case even at low speed or in low-power areas. Notably, for the active e-CVT, the gear ratio $\left(u_{2}=\operatorname{rr}_{\mathrm{CVT}}(t)\right)$ was shifted to a comparatively low value (approximately 0.3-0.4) most of the time, meaning that the engine torque increased while the engine speed decreased. Similar to the optimal energy management case, the SOC drops from $50 \%$ to $39.1 \%$ (10.9\% SOC difference), 


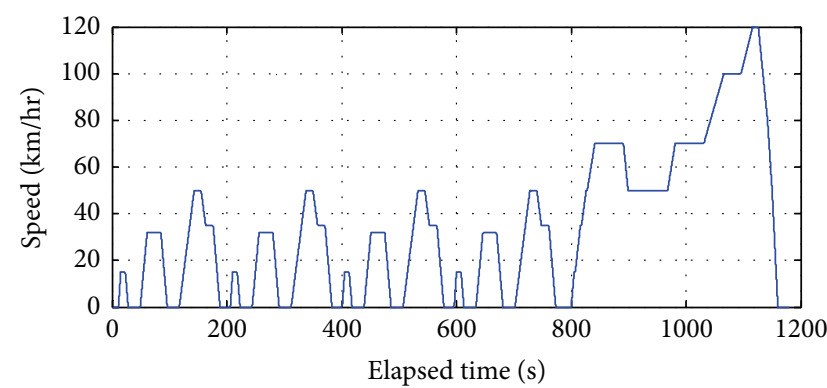

$-V_{d}$ of NEDC

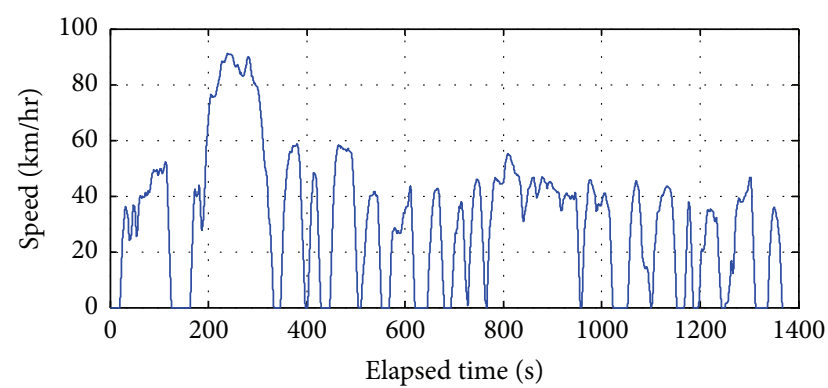

$-V_{d}$ of FTP-72

(a)

(b)

FIGURE 7: Two standard driving cycles: (a) NEDC and (b) FTP-72.

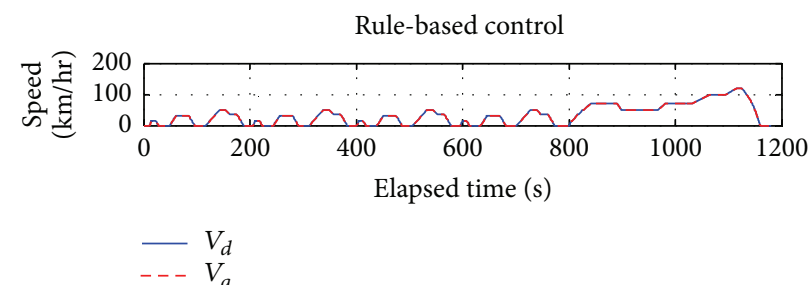

(a)

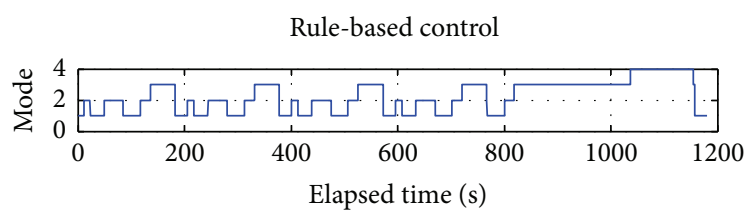

(c)

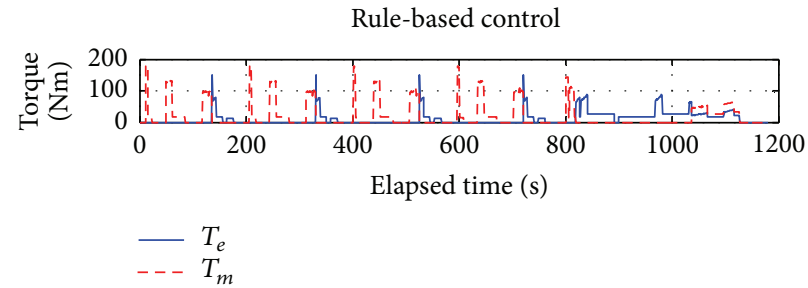

(b)

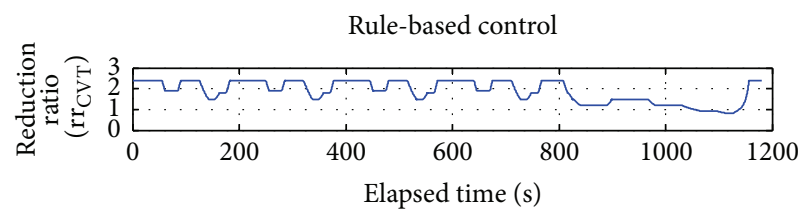

(d)

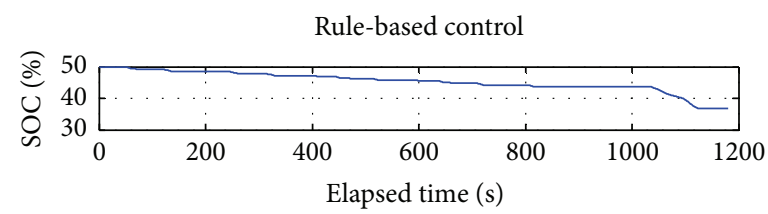

(e)

FIGURE 8: NEDC with rule-based control: driving profile, torque, mode, CVT gear ratio, and battery SOC (from (a)-(e)).

which causes lower electric loss from the battery compared with the rule-based case. Figure 13(a) shows that the engine operates with as high value as possible to decrease the BSFC value. Hence, the fuel economy was better that the two previous cases. In this case, more operation points of the motor were located in the efficient area (medium-speed, medium-torque), where the efficiency was above $85 \%$ (see Figure 13(b)).

For the cases in the FTP-72 driving cycle, a trend similar to those in the NEDC is shown. Because of the reasonable paper length, the simulation results of equivalent fuel consumption are provided in Section 4.3.

4.3. Fuel Economy Improvement. This section discusses the improvement in fuel economy during operation under rulebased, optimal energy management, and optimal energy management/gear-shifting control. Figure 14(a) shows the accumulated equivalent fuel consumption $\left(m_{\mathrm{eq}}\right)$ according to the fitness function expressed in (25) during the NEDC; that is, $m_{\mathrm{eq}}=\int_{0}^{t_{f}} \dot{m}_{\mathrm{eq}}(t) d t$. At the beginning of the cycles, three cases had similar $m_{\text {eq }}$. However, as time elapsed, the differences in accumulated $m_{\text {eq }}$ of the three cases increased. In the high-vehicle-speed (high-power) region after the 800th second, the difference in $m_{\mathrm{eq}}$ increases. Similarly, in Figure 14(b), larger differences of $m_{\mathrm{eq}}$ occur for these three cases as time elapsed. Comparing above three cases, the optimal energy management/gear shifting demonstrated the highest performance.

Table 4 presents a summary of the equivalent fuel improvement during the two driving cycles. For the NEDC cycle, the equivalent fuel consumption ( $g$ ) for the rulebased case, optimal energy management, and optimal energy management/gear shifting were as follows: [1017.10, $830.50,795.66]$. For the FTP-72 cycle, the results were as 


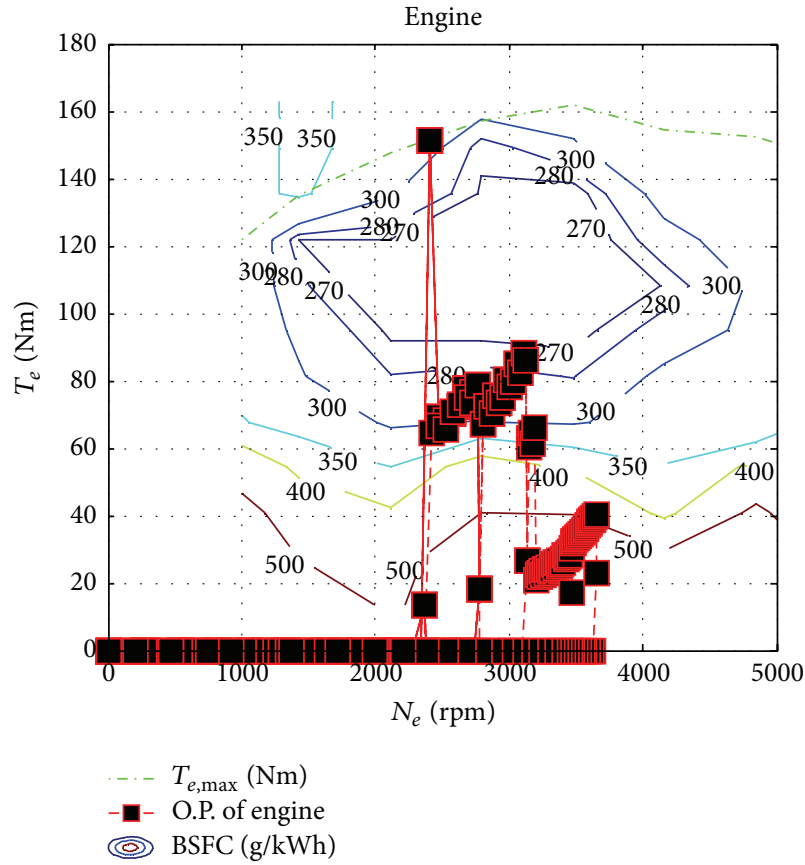

(a)

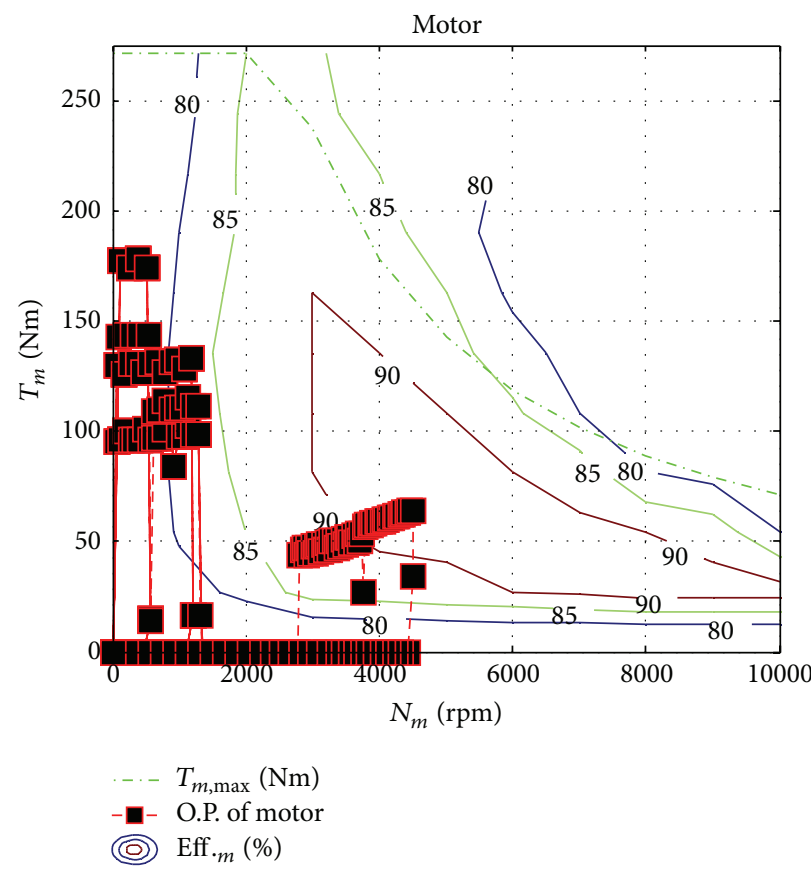

(b)

FIGURE 9: Operation points of (a) engine and (b) motor in the NEDC with rule-based control.

BFA-based optimal energy management

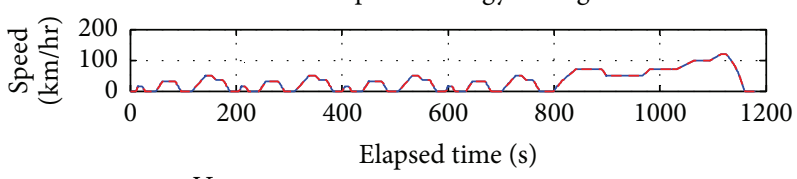$$
-V_{d}
$$

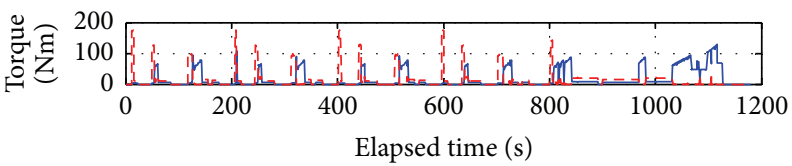

$T_{e}$
$---T_{m}$

(a)

(b)

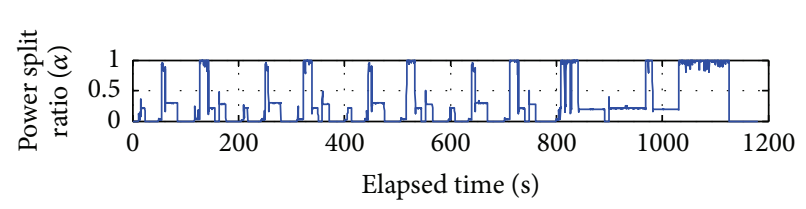

(c)

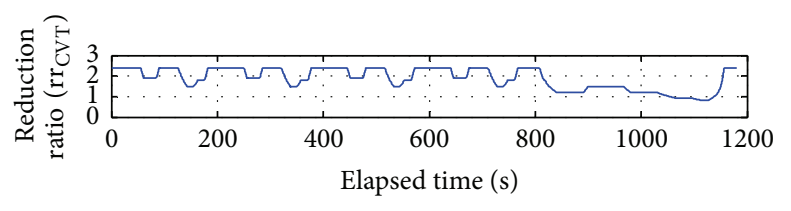

(d)

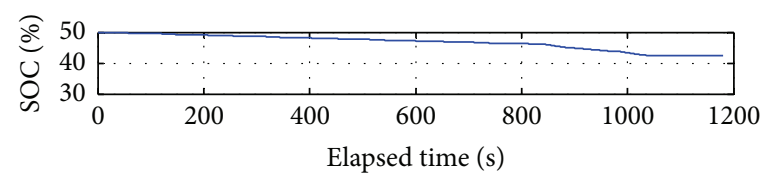

(e)

FIGURE 10: NEDC with optimal energy management: driving profile, torque, mode, CVT gear ratio, and battery SOC.

TABLE 4: Equivalent fuel improvement during two driving cycles.

\begin{tabular}{llccc}
\hline & \multicolumn{2}{c}{ Equivalent fuel consumption (g) } & \multicolumn{2}{c}{ Fuel improvement compared to baseline case (\%) } \\
Driving cycles & NEDC & FTP-72 & NEDC & - \\
\hline Rule-based control & 1017.10 & 1022.10 & - & FTP-72 \\
Opt. energy management & 830.50 & 937.97 & 18.35 & 8.23 \\
Opt. energy management/gear shifting & 795.66 & 888.55 & 21.77 & 13.07 \\
\hline
\end{tabular}




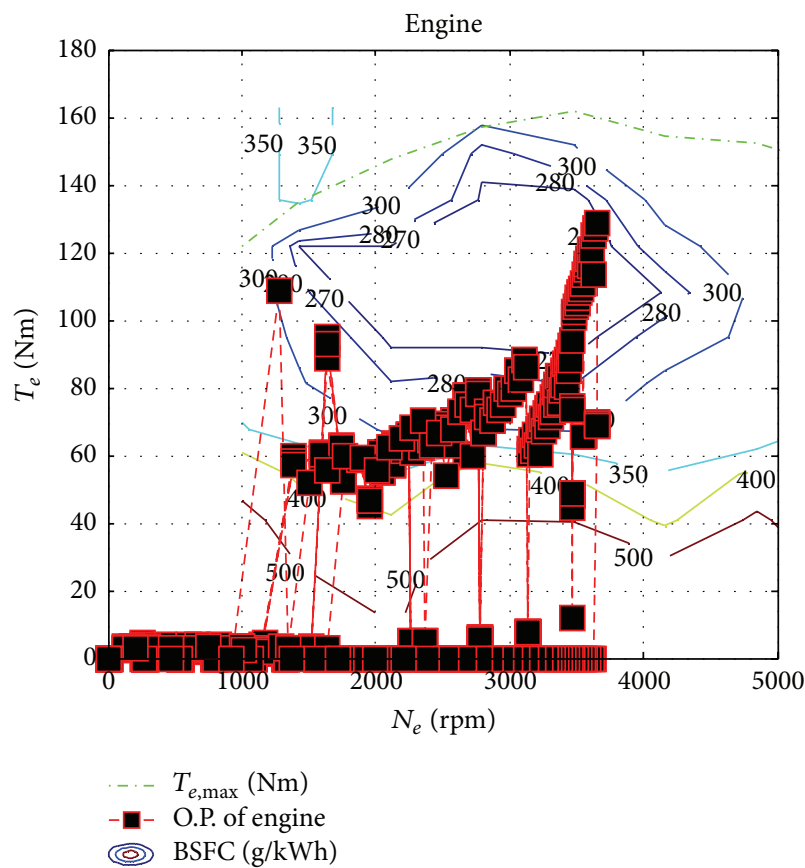

(a)

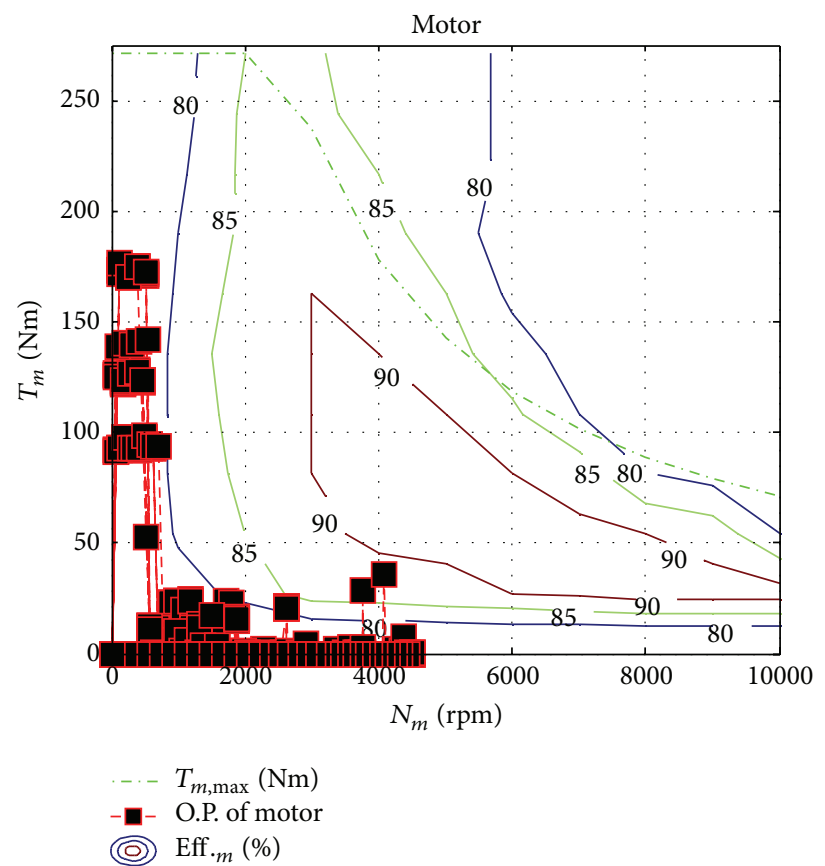

(b)

FIGURE 11: Operation points of (a) engine and (b) motor in the NEDC with optimal energy management.

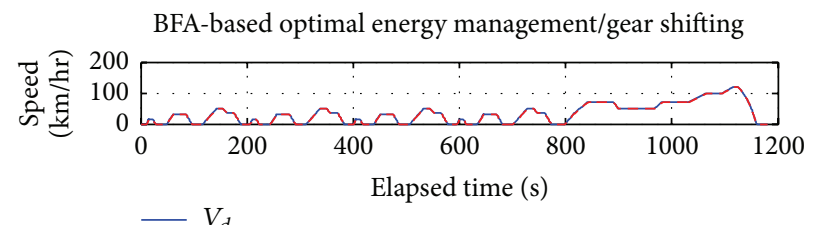

$$
\begin{aligned}
& -V_{d} \\
& ---V_{a}
\end{aligned}
$$

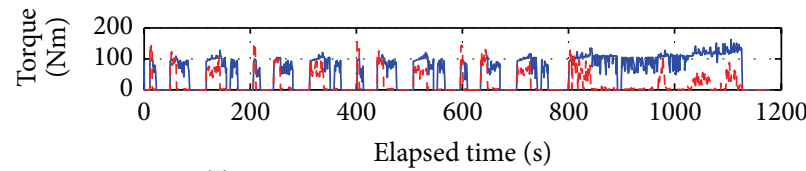

$$
\begin{aligned}
- & T_{e} \\
--- & T_{m}
\end{aligned}
$$
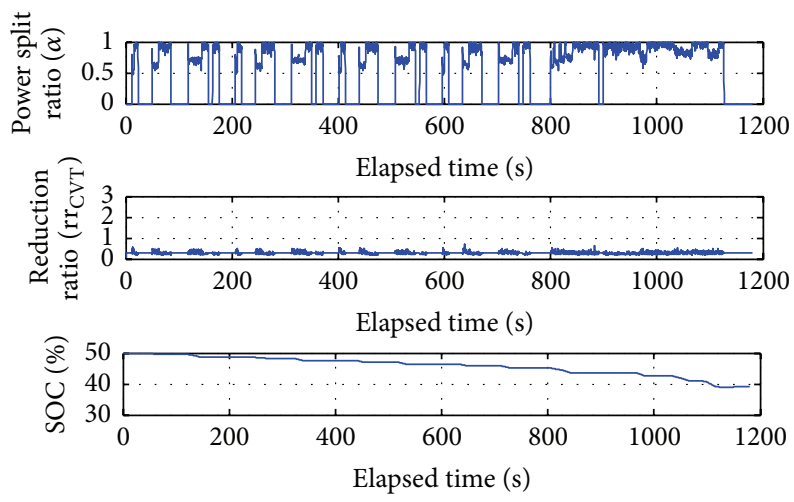

FIGURE 12: NEDC with optimal energy management/gear shifting: driving profile, torque, mode, CVT gear ratio, and battery SOC. 


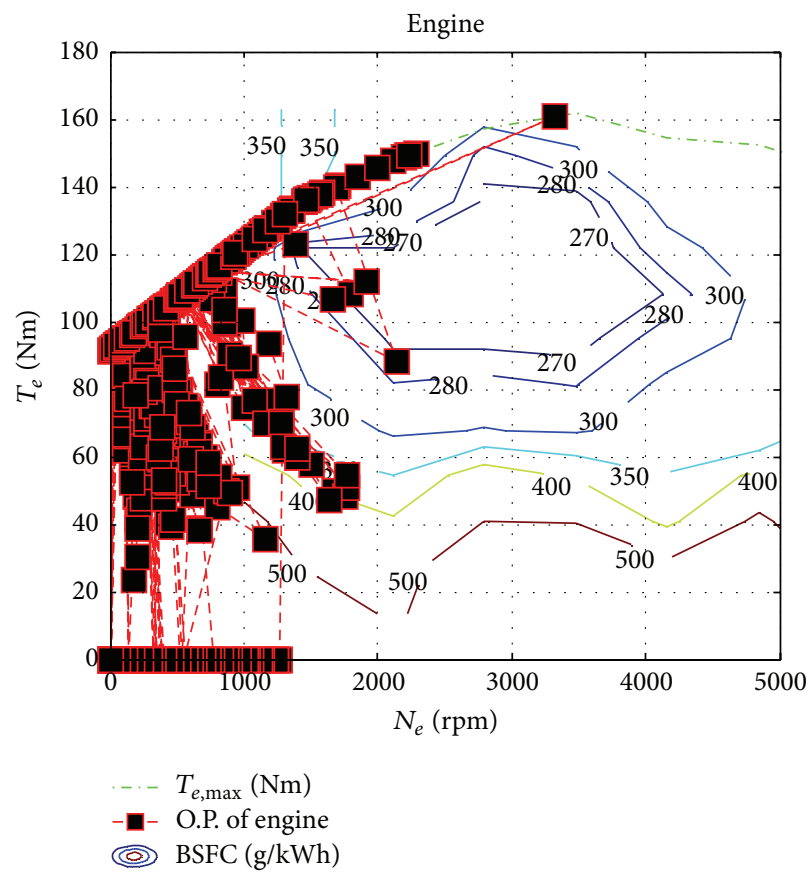

(a)

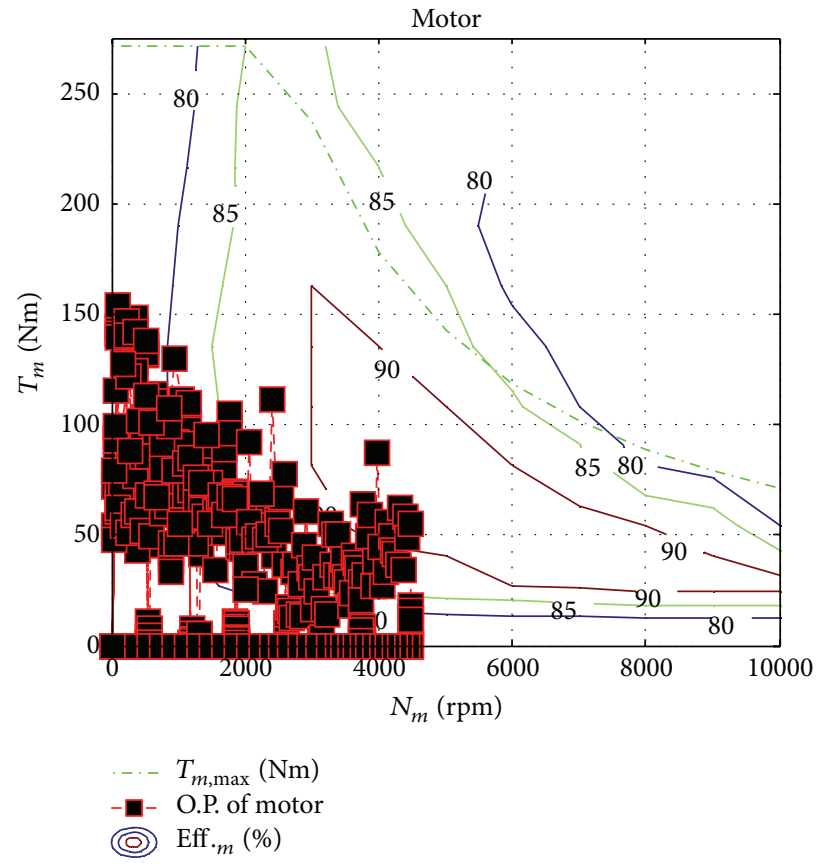

(b)

FIGURE 13: Operation points of (a) engine and (b) motor in the NEDC with optimal energy management/gear shifting.

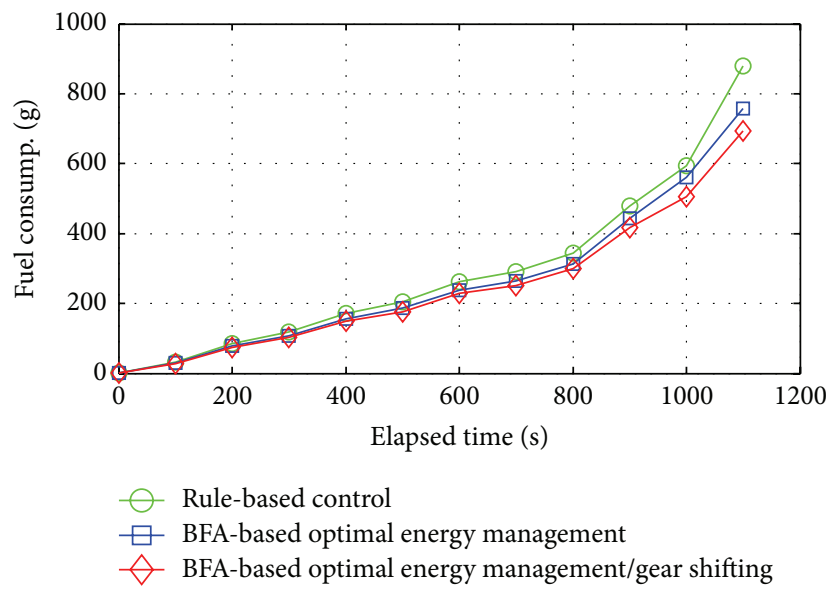

(a)

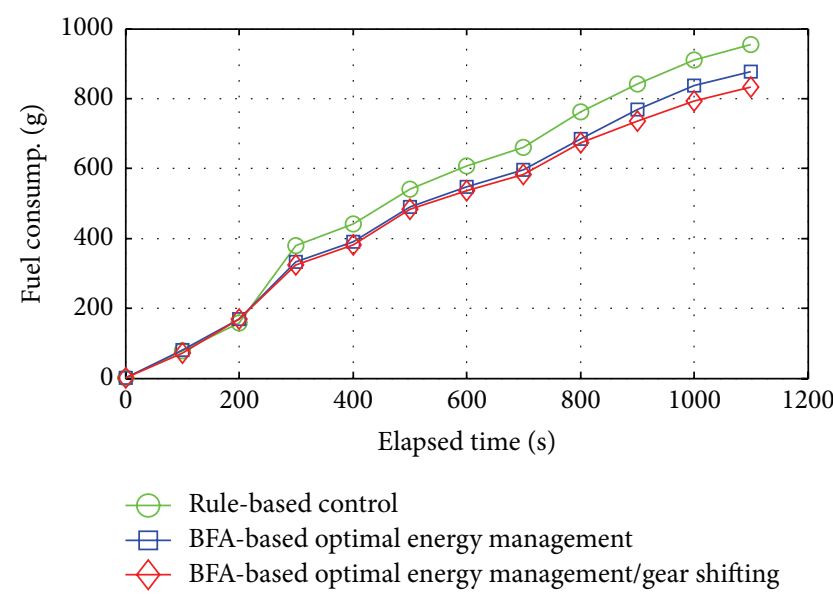

(b)

FIGURE 14: Accumulated equivalent fuel consumption of three cases in (a) NEDC and (b) FTP-72 driving cycle.

follows: $[1129.3,1030.4,973.4]$. According to the data, the fuel improvement compared with the rule-based control for optimal energy management and optimal energy management/gear shifting was $[18.35 \%, 21.77 \%]$ and $[8.76 \%, 13.81 \%]$ for the two driving cycles. The contribution of optimal gear shifting using the BFA for both cycles was $[3.32 \%, 5.05]([(21.77-18.35) \%,(13.81-8.76) \%])$.

The results prove that the BFA largely reduces the equivalent fuel consumption of the e-CVT hybrid powertrains compared with the rule-based case. Hardware-in-the-loop (HIL) real-time simulation and real vehicle verification will be conducted in the future.

\section{Conclusion}

This study developed an integrated energy management/ gear-shifting strategy for e-CVT HEVs by using BFA optimization. The industrial and academic contributions are summarized as follows:

(1) The three steps of BFA for hybrid energy management and CVT control: a three-input (rotational speed, battery SOC, and demanded power) and twooutput (power-split ratio and CVT gear ratio) BFA approach was constructed. The three main steps are elimination-dispersal, reproduction, and chemotaxis 
with a nested for-loop-structural program. The cost function (nutrient concentration) of equivalent fuel consumption was set. The bacterial population was set at five.

(2) Control-oriented e-CVT HEV model: five major Simulink blocks (the driving pattern and driver behavior, engine and traction motor, lithium battery set, e-CVT, and transmission and vehicle dynamics) were constructed. With integration of the BFA Sfunction and two $\mathrm{m}$ files (data and plot), the simulation was completed.

(3) Equivalent fuel improvement: three-case, four-mode, and rule-based control; optimal energy management; and optimal energy management/gear-shifting optimization were compared. With two assigned driving cycles, the improvements in equivalent fuel consumption are $[18.35 \%, 21.77 \%]$ for the NEDC and [8.76\%, 13.81\%] FTP-72 cycle. This verifies that the BFA significantly reduces the consumed energy of eCVT hybrid powertrains.

On a VCU design platform, an HIL environment with realtime simulation will be investigated in the future. A real vehicle integration and dynamometer test will be conducted following the HIL simulation.

\section{Nomenclature}

$A_{f}:$ Area, $\mathrm{m}^{2}$

BSFC: Brake specific fuel consumption, $\mathrm{g} / \mathrm{kW}-\mathrm{h}$

$C$ : $\quad$ Step size of each moving behavior

F: $\quad$ Force, $\mathrm{N}$

FIT: Fitness function

G: $\quad$ Gain

I: $\quad$ Current, A

$m: \quad$ Mass, $g$

$\dot{m}$ : Mass flow rate, $\mathrm{g} / \mathrm{s}$

$N$ : Rotational speed, rpm, or number

P: $\quad$ Power, W

$Q_{b}: \quad$ Electric capacity, Ah

$R: \quad$ Resistance, $\Omega$

rr: Reduction ratio

SOC: State-of-charge

T: $\quad$ Torque, $\mathrm{N}-\mathrm{m}$

$t$ : Time, sec.

$V: \quad$ Vehicle speed, $\mathrm{kph}$, or voltage, $\mathrm{V}$

$\theta: \quad$ Position

$\alpha: \quad$ Power-split ratio

$\eta$ : $\quad$ Efficiency, \%

$\rho: \quad$ Air density, $\mathrm{kg} / \mathrm{m}^{3}$

$\mu$ : $\quad$ Rolling resistance

$\phi$ : Random direction.
Subscripts
a: Actual
b: Battery
brk: Brake
c: Chemotactic step

chg: Charge

CVT: Continuously variable transmission

$d$ : Demand

dchg: Discharge

$e: \quad$ Engine or elimination-dispersal step

$I: \quad$ Integral

$m$ : Motor

oc: Open circuit

p: $\quad$ Proportional or population

pwr: Power

$r$ : Reproduction step

$s: \quad$ Swim or tumble actions

$t$ : Transmission

$v$ : Vehicle

$w$ : Wheel.

\section{Competing Interests}

The authors declare that there is no conflict of interests regarding the publication of this paper.

\section{Acknowledgments}

The authors would like to thank the Ministry of Science and Technology of the Republic of China, Taiwan, for financial support for this research under Contract nos. MOST 103-2511-S-003-061-MY3, 105-2221-E-003-017-MY3, and 1052221-E-150-059.

\section{References}

[1] J. Liang and $\mathrm{Z}$. Wu, "Simulation and optimization of aircooled PEMFC stack for lightweight hybrid vehicle application," Mathematical Problems in Engineering, vol. 2015, Article ID 738207, 11 pages, 2015.

[2] Y.-H. Hung and C.-H. Wu, "A combined optimal sizing and energy management approach for hybrid in-wheel motors of EVs," Applied Energy, vol. 139, pp. 260-271, 2015.

[3] Y. Haitao, Z. Yulan, L. Zunnian, and H. Kui, "LQR-based power train control method design for fuel cell hybrid vehicle," Mathematical Problems in Engineering, vol. 2013, Article ID 968203, 7 pages, 2013.

[4] T. Liu, J. Zheng, Y. Su, and J. Zhao, "A study on control strategy of regenerative braking in the hydraulic hybrid vehicle based on ECE regulations," Mathematical Problems in Engineering, vol. 2013, Article ID 208753, 9 pages, 2013.

[5] K. Ç. Bayindir, M. A. Gözüküçük, and A. Teke, "A comprehensive overview of hybrid electric vehicle: powertrain configurations, powertrain control techniques and electronic control units," Energy Conversion and Management, vol. 52, no. 2, pp. 1305-1313, 2011.

[6] C.-T. Chung and Y.-H. Hung, "Performance and energy management of a novel full hybrid electric powertrain system," Energy, vol. 89, pp. 626-636, 2015.

[7] C.-T. Chung and Y.-H. Hung, "Energy improvement and performance evaluation of a novel full hybrid electric motorcycle with power split e-CVT," Energy Conversion and Management, vol. 86, pp. 216-225, 2014. 
[8] J. L. Torres, R. Gonzalez, A. Gimenez, and J. Lopez, "Energy management strategy for plug-in hybrid electric vehicles. A Comparative Study," Applied Energy, vol. 113, pp. 816-824, 2014.

[9] H. Khayyam and A. Bab-Hadiashar, "Adaptive intelligent energy management system of plug-in hybrid electric vehicle," Energy, vol. 69, pp. 319-335, 2014.

[10] B.-C. Chen, Y.-Y. Wu, and H.-C. Tsai, "Design and analysis of power management strategy for range extended electric vehicle using dynamic programming," Applied Energy, vol. 113, pp. 1764-1774, 2014.

[11] M. Montazeri-Gh, A. Poursamad, and B. Ghalichi, "Application of genetic algorithm for optimization of control strategy in parallel hybrid electric vehicles," Journal of the Franklin Institute, vol. 343, no. 4-5, pp. 420-435, 2006.

[12] G. Paganelli, Y. Guezennec, and G. Rizzoni, "Optimizing control strategy for hybrid fuel cell vehicle," SAE Paper 2002-01-0102, SAE International, 2002.

[13] J. Liu and H. Peng, "Modeling and control of a power-split hybrid vehicle," IEEE Transactions on Control Systems Technology, vol. 16, no. 6, pp. 1242-1251, 2008.

[14] L. Mao, Y. Mao, C. Zhou, C. Li, X. Wei, and H. Yang, "Particle swarm and bacterial foraging inspired hybrid artificial bee colony algorithm for numerical function optimization," Mathematical Problems in Engineering, vol. 2016, Article ID 9791060, 10 pages, 2016.

[15] P. Zhang, F. Yan, and C. Du, "A comprehensive analysis of energy management strategies for hybrid electric vehicles based on bibliometrics," Renewable and Sustainable Energy Reviews, vol. 48, pp. 88-104, 2015.

[16] Z. Chen, C. C. Mi, Y. Fu, J. Xu, and X. Gong, "Online battery state of health estimation based on genetic algorithm for electric and hybrid vehicle applications," Journal of Power Sources, vol. 240, pp. 184-192, 2013.

[17] S. F. Tie and C. W. Tan, "A review of energy sources and energy management system in electric vehicles," Renewable and Sustainable Energy Reviews, vol. 20, pp. 82-102, 2013.

[18] T. Ghanbarzadeh, S. Goleijani, and M. P. Moghaddam, "Reliability constrained unit commitment with electric vehicle to grid using hybrid particle swarm optimization and ant colony optimization," in Proceedings of the IEEE Power and Energy Society General Meeting, pp. 1-7, San Diego, Calif, USA, July 2011.

[19] L. H. Wu, Y. N. Wang, X. F. Yuan, and Z. L. Chen, "Multiobjective optimization of HEV fuel economy and emissions using the self-adaptive differential evolution algorithm," IEEE Transactions on Vehicular Technology, vol. 60, no. 6, pp. 24582470, 2011.

[20] K. M. Passino, "Biomimicry of bacterial foraging for distributed optimization and control," IEEE Control Systems Magazine, vol. 22 , no. 3, pp. 52-67, 2002.

[21] T. K. Das, G. K. Venayagamoorthy, and U. O. Aliyu, "Bioinspired algorithms for the design of multiple optimal power system stabilizers: SPPSO and BFA," IEEE Transactions on Industry Applications, vol. 44, no. 5, pp. 1445-1457, 2008.

[22] S. M. Abd-Elazim and E. S. Ali, "Power system stability enhancement via bacteria foraging optimization algorithm," Arabian Journal for Science and Engineering, vol. 38, no. 3, pp. 599-611, 2013.

[23] E. S. Ali and S. M. Abd-Elazim, "Bacteria foraging optimization algorithm based load frequency controller for interconnected power system," International Journal of Electrical Power and Energy Systems, vol. 33, no. 3, pp. 633-638, 2011.
[24] E. S. Ali and S. M. Abd-Elazim, "Coordinated design of PSSs and TCSC via bacterial swarm optimization algorithm in a multimachine power system," International Journal of Electrical Power and Energy Systems, vol. 36, no. 1, pp. 84-92, 2012.

[25] L. Tan, F. Lin, and H. Wang, "Adaptive comprehensive learning bacterial foraging optimization and its application on vehicle routing problem with time windows," Neurocomputing, vol. 151, no. 3, pp. 1208-1215, 2015.

[26] A. M. Kassem and A. Y. Abdelaziz, "BFA optimization for voltage and frequency control of a stand-alone wind generation unit," Electrical Engineering, vol. 97, no. 4, pp. 313-325, 2015.

[27] A. S. Oshaba and E. S. Ali, "Bacteria foraging: a new technique for speed control of DC series motor supplied by photovoltaic system," WSEAS Transactions on Power Systems, vol. 9, pp. 185195, 2014

[28] B. Bhushan and S. Praliya, "Bacterial foraging algorithm based adaptive control of water bath system," International Journal of Information and Computation Technology, vol. 4, no. 13, pp. 1275-1289, 2014.

[29] A. Almeshal, K. Goher, M. R. Alenezi, A. Almazeed, J. Almatawah, and M. Moaz, "BFA optimized intelligent controller for path following unicycle robot over irregular terrains," International Journal of Current Engineering and Technology, vol. 5, no. 2, pp. 1199-1204, 2015.

[30] S. M. Abd-Elazim and E. S. Ali, "Synergy of particle swarm optimization and bacterial foraging for TCSC damping controller design," WSEAS Transactions on Power Systems, vol. 8, no. 2, pp. 74-84, 2013.

[31] X. Li, D. Yang, and J. Wu, "SVM optimization based on BFA and its application in AE rotor crack fault diagnosis," Journal of Computers, vol. 6, no. 10, pp. 2084-2091, 2011.

[32] V. Rashtchi and M. Darabian, "A new BFA-based approach for optimal sitting and sizing of distributed generation in distribution system," International Journal of Automation and Control Engineering, vol. 1, no. 1, pp. 9-18, 2012.

[33] C. Samanta, S. P. Panigrahi, and B. K. Panigrahi, "Genetic-based bacteria foraging to optimise energy management of hybrid electric vehicles," IET Electrical Systems in Transportation, vol. 4, no. 3, pp. 53-61, 2014.

[34] S.-Y. Chen, Y.-H. Hung, C.-H. Wu, and S.-T. Huang, "Optimal energy management of a hybrid electric powertrain system using improved particle swarm optimization," Applied Energy, vol. 160, pp. 132-145, 2015.

[35] Y.-H. Hung, Y.-M. Tung, and C.-H. Chang, "Optimal control of integrated energy management/mode switch timing in a threepower-source hybrid powertrain," Applied Energy, vol. 173, pp. 184-196, 2016.

[36] V. H. Johnson, "Battery performance models in ADVISOR," Journal of Power Sources, vol. 110, no. 2, pp. 321-329, 2002.

[37] Y.H. Hung and C. W. Hong, "Bond graph dynamics of a rubberbelt continuously variable transmission," International Journal of Vehicle Design, vol. 35, no. 4, pp. 383-398, 2004. 


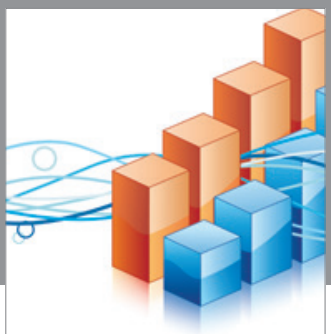

Advances in

Operations Research

vatem alat4

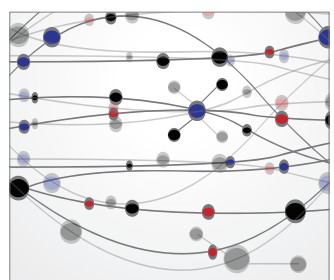

\section{The Scientific} World Journal
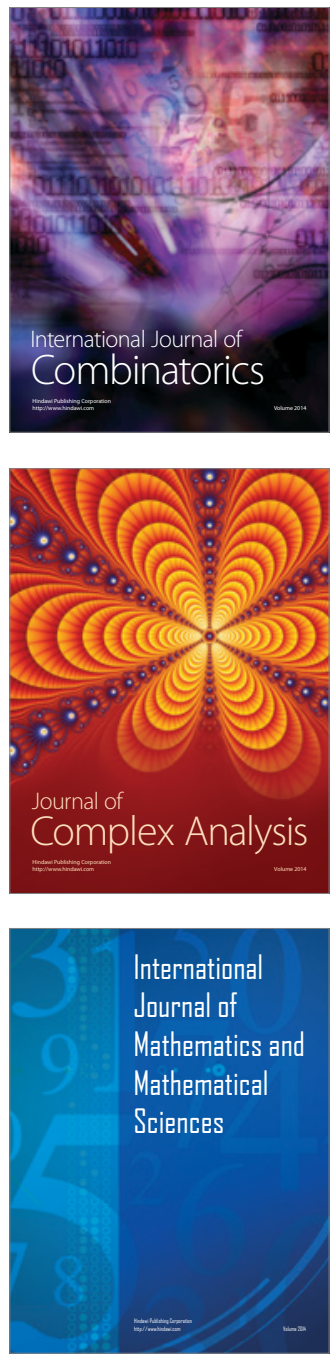
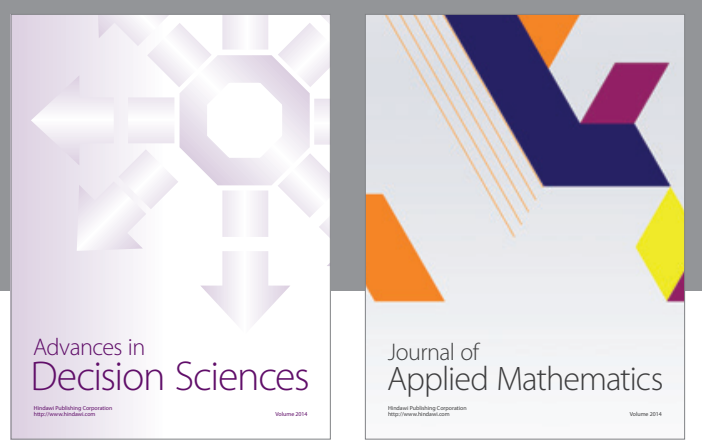

Algebra

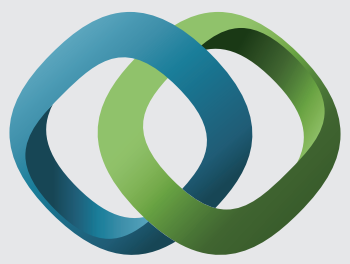

\section{Hindawi}

Submit your manuscripts at

http://www.hindawi.com
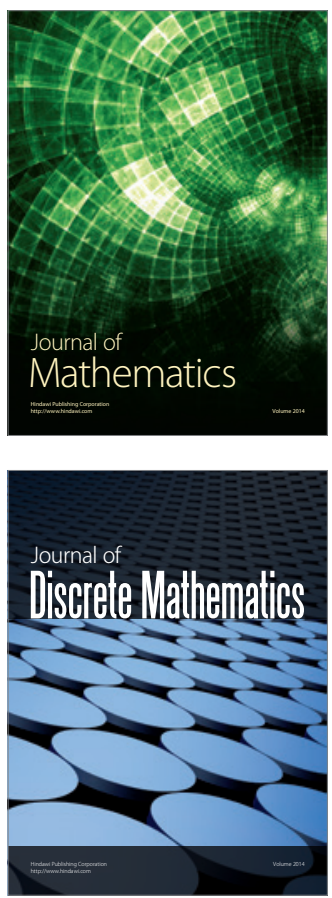

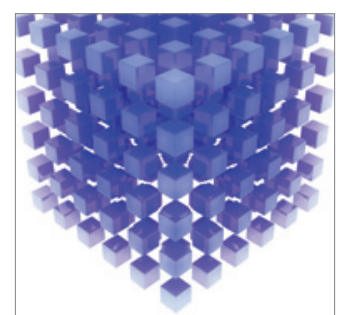

Mathematical Problems in Engineering
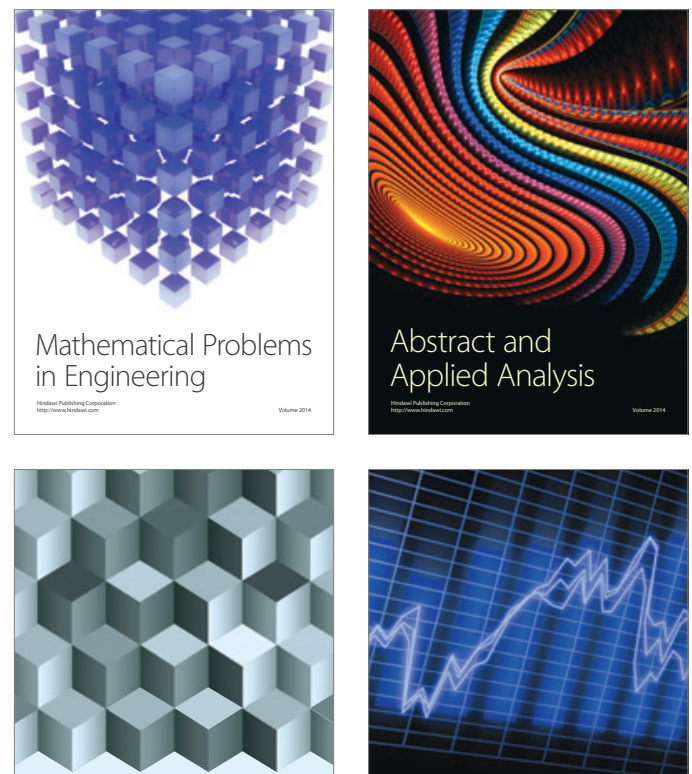

Journal of

Function Spaces

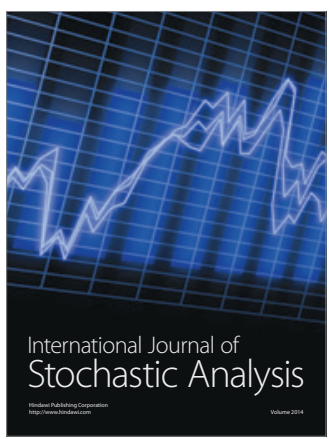

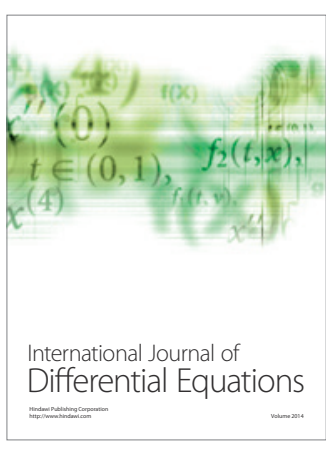
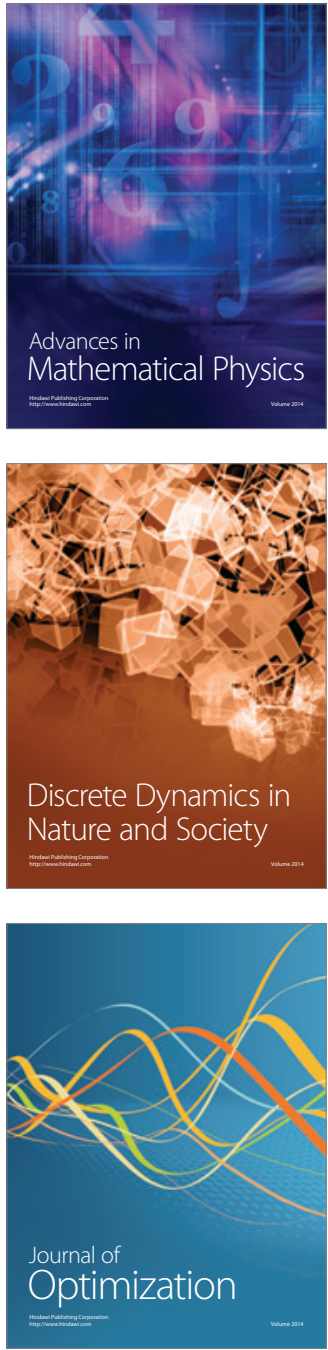